\title{
GENERALIZED WEIGHTED COMPOSITION OPERATORS FROM WEIGHTED BERGMAN SPACES INTO ZYGMUND-TYPE SPACES
}

\author{
XIANGLING ZHU
}

Abstract. The boundedness and the compactness of generalized weighted composition operators from weighted Bergman spaces into Zygmund-type spaces are investigated in this paper. Moreover, we give some estimates for the essential norm of these operators.

Mathematics subject classification (2010): 30H30, 47B38.

Keywords and phrases: Generalized weighted composition operator; weighted Bergman space; Zygmundtype space; essential norm.

\section{REFERENCES}

[1] B. Choe, H. Koo AND W. Smith, Composition operators on small spaces, Integral Equations Oper. Theory, 56 (2006), 357-380.

[2] F. COLONNA AND M. TJANI, Essential norms of weighted composition operators from Hilbert function spaces into the Zygmund-type spaces, Mediterr J. Math., 12 (2015), 1357-1375.

[3] C. Cowen And B. MACCluer, Composition Operators on Spaces of Analytic Functions, CRC Press, Boca Raton, FL, 1995.

[4] K. ESMAEILI AND M. LindSTRÖM, Weighted composition operators between Zygmund type spaces and their essential norms, Integral Equations Oper. Theory, 75 (2013), 473-490.

[5] R. Hibschweiler AND N. Portnoy, Composition followed by differentiation between Bergman and Hardy spaces, Rocky Mountain J. Math., 35 (2005), 843-855.

[6] Q. HU, Y. SHI, Y. SHI AND X. ZHU, Essential norm of generalized weighted composition operators from the Bloch space into the Zygmund space, J. Ineq. Appl., Vol. 2016, Article No. 123, (2016), 16 pages.

[7] O. Hyvärinen, M. Kemppainen, M. Lindström, A. RAutio And E. SAukKo, The essential norm of weighted composition operators on weighted Banach spaces of analytic functions, Integral Equations Oper. Theory, 72 (2012), 151-157.

[8] O. HYVÄRINEN AND M. LINDSTRÖM, Estimates of essential norm of weighted composition operators between Bloch-type spaces, J. Math. Anal. Appl., 393 (2012), 38-44.

[9] H. LI AND X. FU, A new characterization of generalized weighted composition operators from the Bloch space into the Zygmund space, J. Funct. Spaces Appl., Volume 2013, Article ID 925901, 12 pages.

[10] S. Li And S. Stević, Volterra type operators on Zygmund spaces, J. Ineq. Appl., Volume 2007, Article ID 32124, (2007), 10 pages.

[11] S. Li AND S. STEvić, Composition followed by differentiation between Bloch type spaces, J. Comput. Anal. Appl., 9 (2007), 195-205.

[12] S. Li AND S. STEvić, Composition followed by differentiation from mixed-norm spaces to $\alpha$-Bloch spaces, Sb. Math., 199 (12) (2008), 1847-1857.

[13] S. Li AND S. STEVIĆ, Generalized composition operators on Zygmund spaces and Bloch type spaces, J. Math. Anal. Appl., 338 (2008), 1282-1295.

[14] S. Li And S. STEVIĆ, Weighted composition operators from Zygmund spaces into Bloch spaces, Appl. Math. Comput., 206 (2008), 825-831.

[15] S. Li AND S. STEvić, Composition followed by differentiation between $H^{\infty}$ and $\alpha$-Bloch spaces, Houston J. Math., 35 (2009), 327-340. 
[16] S. LI AND S. STEVIĆ, Products of composition and differentiation operators from Zygmund spaces to Bloch spaces and Bers spaces, Appl. Math. Comput., 217 (2010), 3144-3154.

[17] S. Li AND S. STEVIĆ, Generalized weighted composition operators from $\alpha$-Bloch spaces into weighted-type spaces, J. Ineq. Appl., Vol. 2015, Article No. 265, (2015), 12 pages.

[18] Y. LiAng AND Z. ZHOU, Essential norm of the product of differentiation and composition operators between Bloch-type space, Arch. Math., 100 (2013), 347-360.

[19] A. Montes-RodrigueZ, Weighed composition operators on weighted Banach spaces of analytic functions, J. London Math. Soc., 61 (2000), 872-884.

[20] S. STEVIĆ, Norm and essential norm of composition followed by differentiation from $\alpha$-Bloch spaces to $H_{\mu}^{\infty}$, Appl. Math. Comput., 207 (2009), 225-229.

[21] S. STEviĆ, Products of composition and differentiation operators on the weighted Bergman space, Bull. Belg. Math. Soc. Simon Stevin, 16 (2009), 623-635.

[22] S. STEVIĆ, Weighted differentiation composition operators from mixed-norm spaces to weighted-type spaces, Appl. Math. Comput., 211 (2009), 222-233.

[23] S. STEVIĆ, Weighted differentiation composition operators from mixed-norm spaces to the nth weighted-type space on the unit disk, Abstr. Appl. Anal., Vol. 2010, Article ID 246287, (2010), 15 pages.

[24] S. STEvić, Weighted differentiation composition operators from $H^{\infty}$ and Bloch spaces to $n$th weigthed-type spaces on the unit disk, Appl. Math. Comput., 216 (2010), 3634-3641.

[25] Y. WU AND H. Wulan, Products of differentiation and composition operators on the Bloch space, Collet. Math., 63 (2012), 93-107.

[26] W. YANG AND X. ZHU, Generalized weighted composition operators from area Nevanlinna spaces to Bloch-type spaces, Taiwanese J. Math., 16 (2012), 869-883.

[27] Y. YU AND Y. LIU, Weighted differentiation composition operators from $H^{\infty}$ to Zygmund spaces, Integral Trans. Spec. Funct., 22 (2011), 507-520.

[28] K. ZHU, Operator Theory in Function Spaces, Amer. Math. Soc., second edition, 2007.

[29] X. ZHU, Products of differentiation, composition and multiplication from Bergman type spaces to Bers type space, Integ. Tran. Spec. Funct., 18 (2007), 223-231.

[30] X. ZHU, Generalized weighted composition operators on weighted Bergman spaces, Numer. Funct. Anal. Opt., 30 (2009), 881-893.

[31] X. ZHU, Generalized weighted composition operators on Bloch-type spaces, J. Ineq. Appl., 2015 (2015), 59-68.

[32] X. ZHU, Essential norm of generalized weighted composition operators on Bloch-type spaces, Appl. Math. Comput., 274 (2016), 133-142. 